\title{
Perception and Treatment Seeking Behavior for Malaria in Rural Nigeria: Implications for Control
}

\author{
T.A. Okeke ${ }^{1}$ and H.U. Okafor ${ }^{2}$ \\ 1. Department of Community Medicine,College of Medicine, University of Nigeria, Enugu \\ Campus, Enugu, Nigeria \\ E-mail: <thdokeke@yahoo.com> \\ 2. Department of Paediatrics, College of Medicine, University of Nigeria, Enugu Campus, \\ Enugu, Nigeria \\ E-mail: huche57@yahoo.com
}

KEYWORDS Caretakers. Perceptions. Treatment -Seeking. Malaria

\begin{abstract}
The treatment seeking behaviour and perceptions of cause of malaria amongst caregivers of children under-five living in rural Nigeria,was studied using a cross sectional survey conducted in Ugwuogo- Nike ,a rural community in south-east Nigeria, between November 2001 and April 2002. Quantitative and qualitative research methods were employed using structured questionnaires and focus group discussions. Two hundred and seventy-five out of the 300 care givers were mothers and majority $(60.7 \%)$ reported malaria to be a common illness. Heat from the sun was the most popularly reported cause of malaria (49.3\%). Correct knowledge of mosquitoes causing malaria varied significantly with the level of education.. Most of the interviewed caregivers were familiar with signs and symptoms of malaria and self treatment with inappropriate doses of chloroquine was used by the majority (83.7\%) while drug sellers were their most $(52.3 \%)$ popular source of care. Poor utilization of formal health facilities was noted to be due to cost and absence of health personnel. The most popular treatment for severe malaria by caretakers was herbal remedies. Athough some reasonable knowledge of the symptoms of malaria was found, there is still need for intervention measures directed towards correcting misconceptions about the cause of malaria and improving treatment seeking behavior. It is recommended that appropriate home management with early recognition of symptoms and features of severe illness, correct use of effective anti-malaria drugs and prompt referral of severe cases should be promoted since majority resort to self-treatment.
\end{abstract}

\section{INTRODUCTION}

Malaria is the most important parasitic disease in the tropics and remains of highest public health importance. About $90 \%$ of all malaria deaths in the world today occur in Africa, south of the Sahara. An estimated one million people in Africa die from malaria each year and most of these are children under five years old (WHO, 2002). In Nigeria, malaria transmission is holoendemic and more than $90 \%$ of the population lives in areas with stable malaria. It is one of the leading causes of childhood morbidity and mortality with a prevalence rate of $919 /$ 100,000 and is responsible for $25 \%$ and $30 \%$ of infant mortality and childhood mortality respectively. Malaria is responsible for over 300,000 deaths in children annually (FMOH, 1983), most of these deaths result from severe and complicated malaria especially in rural areas (Salako, 1994). Fifty percent of outpatient

Corresponding author: D. H. U. Okafor

Department of Paediatrics, College of Medicine,

University of Nigeria, Enugu Campus, Enugu, Nigeria.

E-mail: huche57@yahoo.com consultations and $15 \%$ to $31.3 \%$ of hospital admissions occur on account of the disease. It is estimated that $92 \%$ of the childhood deaths occur at home (Greenwood et al., 1987), mothers and other caretakers are therefore of foremost importance in recognizing mild or severe malaria disease and seeking treatment for their wards. Most caretakers begin treatment at home with antimalarial drugs and antipyretics purchased over the counter from drug sellers without prescription and usually with inappropriate doses of chloroquine (Derming, 1989; Igun, 1987; Lipowsy, 1992), which often results in poor quality of care and fosters the development of drug resistance(Bermejo, 1993). The ultimate resort after home treatment has failed is the formal health sector.

Prompt and effective treatment of all children with malaria is a critical element of malaria control. People who become ill with the disease need prompt and effective treatment to prevent the development of severe manifestations and death (WHO 2003). Early treatment depends upon prompt recognition of symptoms and signs of malaria in the household, mainly by women. Early 
treatment also requires that appropriate health services and medication are accessible and utilized (Tanner et al.., 1998).

The success of this strategy depends on the behavior of patients and caretakers of young children and it has been documented that treatment seeking behavior is related to cultural beliefs about the cause and cure of illness (Bledsoe et al., 1985). In some cases, illnesses are seen as amenable to treatment by modern practitioners, while others are considered best treated by traditional healers (Press, 1980). Illness ideas and behaviors may enhance or interfere with the effectiveness of control measures (Klein et al., 1995).

An understanding of communities' beliefs and behaviors is therefore crucial to the success of a specific control measure. This study aims to ascertain the current perception of cause and treatment seeking practices of caretakers in a rural area in order to identify probable areas of intervention for the control of malaria in the under-fives.

\section{METHODOLOGY}

The Study Area: The study was conducted in Nike, in Enugu-East local government area (LGA). It is a rural area situated about 20 kilometers east of Enugu, the capital of Enugu State, Nigeria. Enugu is located between latitude $5^{0} 55^{\prime \prime}$ and $7^{0} 10^{\prime \prime}$ north, longitude $6^{0} 50^{\prime \prime}$ and $7^{0} 55^{\prime \prime}$ east. The population is mainly of Christian religion; ethnically Igbo, most are farmers and petty traders. The vegetation is a mixture of rainforest and Savannah types while rainfall is seasonal and occurs between the months of March and October. There are no good roads, no pipe-borne water supply nor electricity in the area. Malaria is holoendemic in the area and Ugwogo-Nike, one of the four autonomous communities in Nike was randomly selected as the study area. It is made up of 10 villages and has a population of about 9224 of whom 1748 (18.5\%) are children under- five years old (project census). It has one primary school and one secondary school. There is a primary health centre and a comprehensive health centre (Cottage hospital), which serve the community.

Study population: This comprised of caregivers in households with children under five years old within the study community.

Ethical Issues: Ethical approval for the study was obtained from the Ethical Committee of the University of Nigeria Teaching Hospital, Enugu (UNTH). Verbal informed consent was obtained from the study participants before the research instruments were administered. Confidentiality of all information obtained from participants was maintained by not allowing information to be accessible to non-members of the research team.

Study Design: This was a descriptive crosssectional study, conducted between November 2001 and April 2002, in which both qualitative and quantitative research methodologies were employed. The quantitative component was in the form of a household survey in which an interviewer administered, pre-tested structured questionnaire was used to elicit information on caretakers' socio-demographic characteristics, knowledge, beliefs, and treatment seeking practices with regards to malaria. The qualitative aspect comprised of focus group discussions (FGD), in which caretakers of children under five were the target.

Data Collection: Thirty questionnaires were pre-tested on another community with similar characteristics as the study community; and subsequently the study instrument was modified accordingly. Households with children under five years were identified from a community census and this provided the sampling frame from which 300 house holds were selected using a systematic random sampling method. The six interviewers used were indigenes of the area that could speak the local "Igbo" dialect and were trained in interviewing techniques.

The qualitative aspect comprised of focus group discussions (FGD), in which caretakers of children under five were the target. Since caretakers are usually women only females were selected; other criteria for selection of the respondents included, age and educational background. Groups were as follows:-No formal education, primary school education, Secondary $\&$ Post secondary school education; young $=30$ years and below, old $=31$ years and above. A total of six FGDs were conducted and each lasted 45-60 minutes. Information obtained from the FGDs included knowledge, beliefs, treatment and health- seeking behaviors of caregivers in relation to malaria.

The recorded proceedings from the qualitative data was transcribed and analyzed manually by content analysis. The quantitative data was analyzed using EPINFO 6 statistical software. 


\section{RESULTS}

A total of 300 interviews were conducted, most of the caretakers, 275 (91.7\%) were mothers, followed by $10(3.3 \%)$ who were grandmothers, 9 $(3 \%)$ were fathers and the least number, $6(2 \%)$ were another relative.

The socio-demographic characteristics of caretakers are shown in table 1. Majority of the respondents, $106(35.4 \%)$ were aged 35-44years and most of them $(73 \%)$ attained primary education. The large majority of caretakers were Christians (94\%) and farmers (64.3\%) while civil servants were in the minority $(2 \%)$.

The most commonly reported illness associated with fever was malaria as reported by 191(63.7\%) respondents, followed by measles $165(55.0 \%)$ convulsion $116(38.7 \%)$, cough 103 $(34.3 \%)$ and diarrhea from $76(25.3 \%)$ respondents. The less common ones were catarrh, pneumonia and typhoid fever from 4,3 and 3 respondents respectively.

Malaria is referred to locally as Iba, however two types of Iba were described, "Iba nkiti" which is "ordinary" Iba and "Iba ocha na anya" which is "yellow" Iba that causes yellowish discoloration of the eyes and is regarded as the serious variety.

Table 1: Socio-demographic characteristics of respondents

\begin{tabular}{lrr}
\hline $\begin{array}{l}\text { Demographic } \\
\text { characteristics }\end{array}$ & $\begin{array}{l}\text { Number of } \\
\text { respondents }\end{array}$ & $\%$ \\
\hline Age & 24 & 8.0 \\
15-24 & 97 & 32.3 \\
$25-34$ & 106 & 35.4 \\
$35-44$ & 63 & 21.0 \\
$45-54$ & 10 & 3.3 \\
55 and above & 9 & 3.0 \\
Sex & 291 & 97.0 \\
Male & & \\
Female & 275 & 91.7 \\
Status in Family & 9 & 3.0 \\
Mother & 10 & 3.3 \\
Father & 6 & 2.0 \\
Grandmother & 81 & 27.0 \\
Others & 174 & 58.0 \\
Level of Education & 32 & 10.7 \\
No formal education & 13 & 4.3 \\
Primary & & \\
Secondary & 20 & 6.7 \\
Post secondary & 66 & 22.0 \\
Occupation & 193 & 64.3 \\
Housewife & 2 & 0.7 \\
Trader & 2 & 0.7 \\
Farmer & 17 & 5.7 \\
Civil servant & \\
Teacher & & \\
Others &
\end{tabular}

Table 2: Causes of malaria as reported by the respondents

\begin{tabular}{lcc}
\hline Causes of malaria & No. of responses & $\%$ \\
\hline Too much sun & 148 & 49.3 \\
Mosquitoes & 119 & 39.7 \\
Fried food & 113 & 37.7 \\
Hard work & 96 & 32.0 \\
Cold weather & 58 & 19.3 \\
Dirty environment and flies & 42 & 14.0 \\
Weakness & 18 & 6.0 \\
Alcohol & 17 & 5.7 \\
Don't know & 14 & 4.7 \\
Other & 8 & 2.7 \\
\hline
\end{tabular}

Different terms are used to describe convulsion, these were Dimgba and Ihe odido.

Local Perception of Cause and Recognition of Malaria: Malaria was perceived to be caused by various factors (Table 2). As some mothers explained in the FGD "the sun can cause malaria by either shinning directly on the child or on the breast of a lactating mother, if she stays too long under the sun, especially while at work in the farm, the breast milk will heat up and when that child eventually sucks, it will cause malaria".

The correct knowledge of mosquitoes as a cause of malaria varied with level of education. These differences were found to be statistically significant $\left(\chi^{2}=18.8, \mathrm{df}=3, \mathrm{p}<0.05\right)$. One hundred and twelve $(37.3 \%)$ of the respondents were aware that mosquito bites transmit malaria. It is also believed that malaria can be acquired in other ways such as through breast milk according to $80(26.7 \%)$ respondents, from bodily contact 46 $(15.3 \%)$, drinking dirty water $44(14.7 \%)$, inhalation 26 (8.7\%) and sharing the same cup 34 $(11.3 \%)$. The least number $5(1.7 \%)$ felt it is inborn. Some of the responses on the mode of transmission at the FGD"S are noted below;

"If you drink bad water, the person will get malaria".

"Mosquitoes cause malaria by perching on dirty things which can be transmitted into a persons blood after a bite and cause iba".

Having the correct knowledge that mosquito bites transmit malaria was significantly influenced by level of education: $22(19.8 \%)$ for no education, $39(35.1 \%)$ for primary education, $59(53.1 \%)$ for secondary education and $51(46.2 \%)$ for post secondary. $\left(\chi^{2}=14.14, \mathrm{df}=3, \mathrm{p}<0.05\right)$. Symptoms of malaria and features of severe illness as perceived by respondents are shown in Table3. Most of the symptoms mentioned by the 
Table 3: Symptoms of malaria

\begin{tabular}{lcc}
\hline Symptoms/features of (Malaria) & \multicolumn{2}{l}{$\begin{array}{l}\text { No. (\%) of } \\
\text { respondents }\end{array}$} \\
\hline Weakness & $146(48.7)$ \\
Chills & $140(46.7)$ \\
Headache & $129(43.0)$ \\
Yellow urine & $108(36.0)$ \\
Sweating & $31(10.30)$ \\
Fever & 23 & $(7.7)$ \\
Diarrhea & 20 & $(6.7)$ \\
Abdominal pain & 19 & $(6.3)$ \\
\hline
\end{tabular}

respondents seemed to reflect correct clinical symptoms of malaria.

Majority of respondents, 178 (59.3\%) mentioned high fever as a symptom suggestive of a severe illness (see Table 4). Convulsion was recognized as a symptom of severe illness, which killed children easily. Most respondents are of the view that it is not malaria that causes convulsion but the high fever associated with malaria. Some of the mothers attributed the cause of convulsion to cold weather saying that "If rainy season or cold weather comes, it causes fever which results in convulsion”.

Table 4: Features of severe illness as perceived by respondents

\begin{tabular}{|c|c|}
\hline Symptoms/features(severe illness) & No. (\%) of respondents \\
\hline High fever & $178(59.3)$ \\
\hline Inability to eat & $175(58.3)$ \\
\hline Drowsiness & $105 \quad(35)$ \\
\hline Convulsion & $80 \quad(26)$ \\
\hline Inability to sit or stand & $48(17.4)$ \\
\hline Repeated vomiting & $46 \quad(16)$ \\
\hline Yellowish discoloration of eyes & $60 \quad(20)$ \\
\hline Unconsciousness & $23(8.7)$ \\
\hline Diarrhea & $14 \quad(5.3)$ \\
\hline
\end{tabular}

Treatment and Care-Seeking Behavior: The preferred sources of care for the treatment of the most recent attack of malaria are shown in figure 1. Drug sellers were the most popular source of care $138(52.3 \%)$ followed by home treatment with herbal remedies, $51(19.3 \%)$ and drug hawkers 22 $(8.3 \%)$. When this is summarized, self treatment was used by $221(83.7 \%)$ respondents, formal sector by $31(11.7 \%)$ and traditional healers by $21(4.5 \%)$. Traditional healers are not usually consulted for mild illnesses. Use of herbal remedies at home was the second most popular form of treatment for febrile illness. For those who indulge in herbal treatment, several methods are practiced which are explained by these quotes from the respondents. "If the fever starts, we pluck guava or paw-paw or mango leaves, cook the leaves and use it to bath the child and give him to drink"..

While most of the caretakers recognized the use of orthodox medicine to treat malaria, majority patronized drug sellers first and if symptoms persist, they go to the hospital. Some will also take herbal medicine first before resorting to orthodox medicine.

When asked about the reasons for not using the government owned local health facility the majority, 115(38.3\%) reported cost of treatment. Other reasons given included unavailability of a doctor $114(38 \%)$, unavailability of other health workers 51(17.0\%), prolonged waiting time 50 (16.7\%), drugs not available $31(10.3 \%)$, poor attitude of staff $21(7 \%)$ and distance $7(2.3 \%)$. Results of the FGD revealed that they would rather go to the health facilities in the capital city, $20 \mathrm{~km}$ away where a doctor is always available. The cost of treatment in the health facility ranges from 300 naira to 2000 naira (about \$2- \$13) for a child's illness, which they felt was high. They claimed they prefer to go to the drug sellers because they are always available even in the evenings and their drugs are cheaper. In addition there was an option of using credit facility with drug sellers.

A good number of the respondents would indulge in home treatment with paracetamol and chloroquine and if the fever persists, they will visit the drug seller before the health center. However when the malaria is severe and the child is convulsing, majority of the respondents, $40(60 \%)$ took their children to the traditional healer for treatment. Other sources of care for severe cases were home herbs 10 (14.3\%), drug sellers $6(8.6 \%)$, private clinic $2(2.6 \%)$ and the local government health centre $4(5.7 \%)$. Others went to the government-owned secondary health facility, the Park lane hospital 3 (4.3\%) and the tertiary health facility ,the University of Nigeria Teaching Hospital(UNTH), 2 (2.6\%). Both are located within the capital city Enugu, about $20 \mathrm{~km}$ from the study site.

A different herbal treatment is applied when the child is convulsing. One of the respondents stated that "if he starts convulsing, you take the child to the people (herbalist) that will give the child incisions with razor blade, blood will come out and then you rub in the herbs". Another method of herbal treatment employed by some of the mothers is the use of Palm kernel oil, "Ude Aku." 


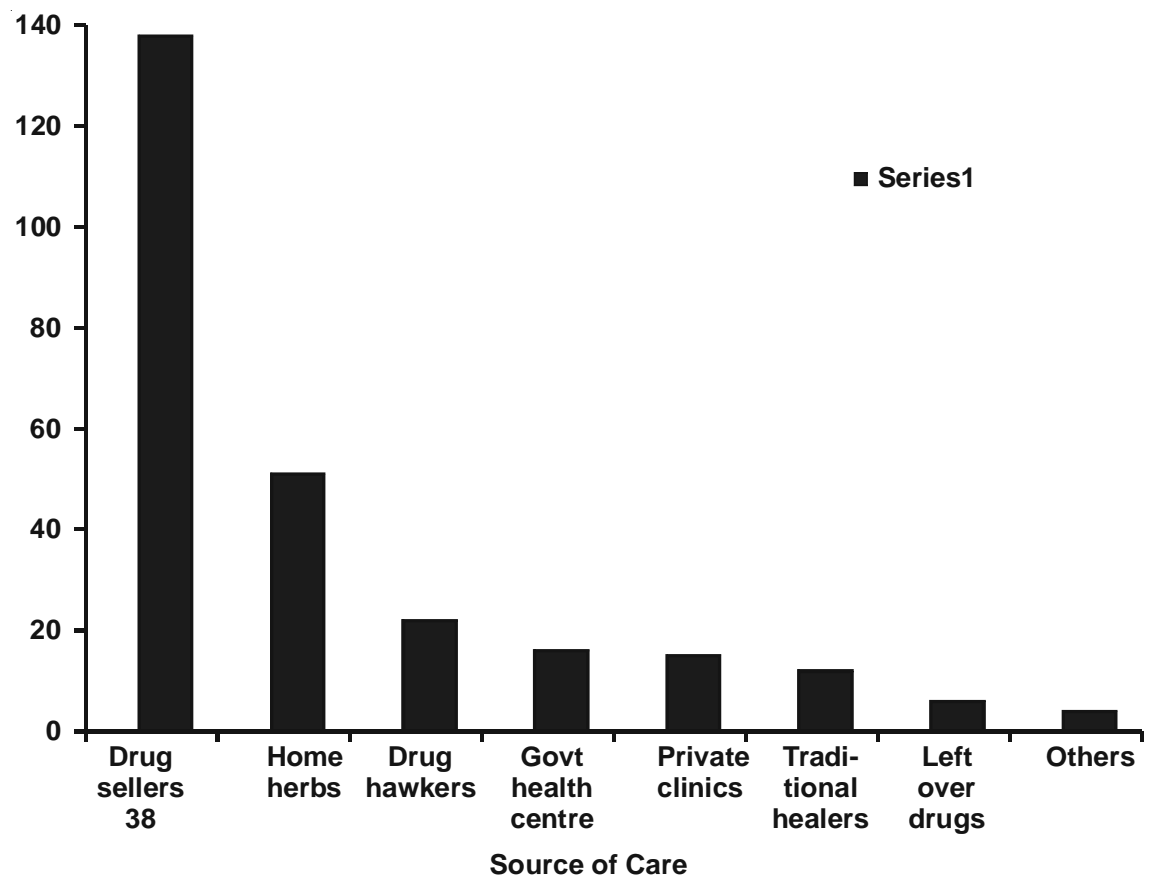

Fig. 1.

\section{DISCUSSION}

In this study, it was observed that majority of the caretakers were women, similar to findings reported elsewhere (Raikes, 1989).The norm being that the well-being of the child is the joint responsibility of the parents; the women as caregivers and the men as providers and decision makers (Oberlander, 2000).

The classification of malaria into subtypes ; "ordinary" and "yellow", as seen in this study, had also been reported in the western part of Nigeria where mothers perceived different types of malaria including "cold" "yellow" and "ordinary" varieties (Brieger, 1994). In Nsukka area of eastern Nigeria people describe "ordinary", "colored", "wet", "dry" and "shaking" malaria (Breiger, 1996). These differences we believe may depict the various levels of severity of the illness as suggested by our findings in this study and may have some important implications when planning health education programmes in the various communities. The commonest perceived cause of malaria in this study was due to heat from too much sun, eating of fried food, doing hard work, cold weather were also mentioned as causes of malaria. Heat from the scorching sun and eating fried or oily food was also noted in the study conducted in Southern Ghana (Ahorlu, 1997). Cold weather, which was mentioned by $19.3 \%$ in this study, was implicated in the Ethiopian study where $34.3 \%$ believed malaria was caused by cold; clouds; rains (Yenenah, 1993).

In this study just over a third $(39.7 \%)$ of those interviewed mentioned mosquitoes as a cause of malaria. This is similar to a previous study conducted in Kenya where $36.4 \%$ were aware of mosquitoes as a cause of malaria (Ongore, 1989). The implication is that these misconceptions regarding the cause of malaria would definitely have a negative impact on campaigns promoting the various anti-vector measures like insecticidetreated nets. (ITN's). Obviously if mosquitoes are not associated with malaria transmission, the need to prevent mosquito bites using bed nets cannot be properly appreciated (WHO, 2003). However a study conducted in Ghana showed that understanding of an association between mosquitoes and malaria did not predict bed net usage and that the primary reason for bed net usage pointed to avoidance of the nuisance of mosquito bites and not necessarily for prevention of malaria (Agyepong, 1999). 
Self-medication was found to be a common practice amongst the caretakers, and the usual pattern of treatment began at home with herbal remedies or drugs purchased from drug sellers which were administered inappropriately. It is only when home treatment is obviously not working that the child is then taken to a health facility thereby resulting in delay and possible complications. It has also been reported elsewhere that a high proportion of malaria episodes are often treated at home and that selfmedication is a common practice (Derming et al.,, 1989). In this study only $10.3 \%$ of caretakers reported taking a sick child to the health facility while $85.7 \%$ were treated at home. In a previous study conducted in Nigeria, a high rate of home treatment was also observed (Salako, 2001). Greenwood et al.,. (1987) suggested that home treatment of malaria has some potential advantages and if done appropriately, increase the proportion of children receiving anti-malarial therapy and facilitates prompt treatment, possibly preventing some of the complications of malaria. These considerations have recently led some authors to advocate improving self-medication practices of the population as a necessary measure towards more effective malaria control (Breman et al.,, 1988; Foster, 1995). Hence interventions to improve home management in our study community will be very beneficial and help reduce morbidity and mortality.

As noted earlier the ultimate resort after home treatment has failed is the formal health sector. The reasons for non-utilization of health facilities in this study included, non-availability of a doctor, poor attitude of staff, lack of access because of cost, prolonged waiting time, unavailability of drugs and distance from home. Similar findings were noted in other studies (Igun, 1987; Ruebush, 1995; Ahorlu, 1997). Caretakers would rather take ill children to health facilities in Enugu , the capital city which is about $20 \mathrm{~km}$ away ,because they are sure there will be a doctor to attend to them. The mothers seldom consulted the traditional healers for mild illnesses. The relatively minimal use of traditional healers for treatment of uncomplicated malaria observed in this study was also noted in previous studies (Agyepong, 1990; Espino, 1992). The implication is that they are not important providers of treatment for mild febrile illnesses. Therefore, the traditional healers are not targets for intervention measures aimed at providing optimal care for cases of non-severe malaria. There was no perceived relationship between malaria and convulsions, by the care-givers, therefore mild and severe malaria are regarded as distinct conditions with different local terms, etiological factors, symptoms and treatment. Some also believed convulsion to be due to evil spirits. In Africa it is a common belief that convulsions are of spiritual origin and therefore treated from that point of view (Mwenesi et al., 1995; Winch et al., 1996). The majority of mothers would resort to traditional healers if the illness got worse, since complications such as convulsion was perceived to be better managed by them (Mwenesi, 1993) thereby resulting in considerable delay before seeking care in a health facility, if at all. The most popular method of treatment for severe malaria by caretakers was by administering herbal remedies, some containing dangerous components such as putting "Ude Aku" into the eyes and placing their feet over fire. "Ude Aku" ie palm kernel oil which was popular could cause chemical conjunctivitis when applied to the eyes, which may lead to blindness and placing their feet over fire could cause burns. Use of dangerous components for care was also reported in the western part of Nigeria where cow urine was used (Ramakrishna et al., 1988, 1989). This results in considerable delay in referral to a health facility as was also found in coastal Tanzania (Makemba et al., 1996).

\section{CONCLUSION}

Malaria is recognized as a major health problem by the caretakers of children under- five in the study community. The study has revealed reasonable knowledge of the symptoms of malaria, however there is a need for community intervention programmes directed towards correcting misconceptions about the cause of malaria, the recognition of danger signs which will require prompt referral to health facilities and improving health seeking practices. Appropriate home management with effective drugs given in correct dosages should also be promoted since majority resort to self-treatment.

\section{ACKNOWLEDGEMENT}

This investigation received financial support from the UNDP/World bank/WHO Special Programme for Research and Training in Tropical Diseases (TDR). 


\section{REFERENCES}

Agyepong, I.A.: Socio-cultural and clinical factors affecting the transmission of malaria: A study among adolescent girls in rural Ghana. WHO/TDR Final Report, S20/181/532 (1990).

Ahorlu, C.K., Dunyo, S.K., Afari, E.A., Koran, K.A. and Nkrumah, F.K.: Malaria related beliefs and behaviors in southern Ghana. Implications for treatment, prevention and control. Trop. Med. Int. Health, 2(5): 488-499 (1997).

Bermejo, A. and Berkni, A.: Community participation in disease control. Soc. Sci. Med., 36: 1145-1150 (1993)

Bledsoe, C.H., Goubaud, M.F.: The Reinterpretation of Western Pharmaceuticals among the Mendes of Sierra Leone. Soc. Sci. Med., 21(3): 275 (1985).

Breman, J.G. and Campbell, C.C.: Combating severe malaria in African children. Bull. WHO, 66(5): 611 (1988).

Brieger, W.R.: Pile sorts as a means of improving the quality of survey data: Malaria illness symptoms Health Educ. Res., 9:257-260 (1994).

Brieger, W.R., Nwankwo, E., Ezike, V.I., Sexton, J.D., Breman, J.G., Parker, K.A and Robinson, T.: Sociobehavioral baseline for implanting a strategy of insecticide impregnated bed nets and curtains for malaria control a Nsukka, Nigeria. International Quarterly of Community Education, 16(1): 47 (1996-97).

Deming, M.S., Gayibor, A., Murphy, K., Jones, T.S, Karsa, T.: Home treatment of febrile children with antimalarial drugs in Togo. Bull. WHO, 67: 695700(1989)

Espino, E.: Socio-behavioral research of endemic malaria in the Philippines: Implications for control, WHO/ TDR/SER Progress Report, S20/181/85 (1992).

Federal Ministry of Health, Nigeria. Annual Report 1980-83 (1983)

Foster, S. Treatment of malaria outside the formal health services. J. Trop. Med. Hyg,, 98(1): 29-34 (1995).

Greenwood, B.M., Bradley, A.K. and Greenwood A. M.: Mortality and Morbidity from Malaria among children in a rural area of Gambia, West Africa. Trans. Roy. Soc. Trop. Med. Hyg., 81: 478-486 (1987).

Igun, U.A.: Why we seek treatment here: retail pharmacy and clinical practice in Maiduguri, Nigeria. Soc. Sci. Med., 24: 689(1987),

Klein, R.E, Weller, S.C., Zeissig, R., Richards, F.O. and Reubush, T.K.: Knowledge, beliefs and practices in relation to malaria transmission and vector control in Guatemala. Am. J. Trop. Med. Hyg., 52: 383388(1995).

Lipowsky, R., Kroeger, A and Vasquez, M.L. Sociomedical aspects of malaria control in Columbia. Soc.Sci.Med., 34(6): 625(1992).

Mwenesi, H.A. Mother's definition and treatment of child hood malaria on the Kenyan coast. Final Report, WHO/TDR/SER (1993).

Mwenesi, H., Harpham, T. and Snow, R.W.: Child malaria treatment practices among mothers in Kenya .Soc. Sci. Med., 40: 1271-1277(1995).

Nevill, C.G., Some, E.S., Mung'ala, V.O., Mutemi, W., New, L., Marsh, K., Lengeler, C. and Snow, R.W.:
Insecticide treated bed nets reduce mortality and severe morbidity from malaria among children on the Kenyan coast. Trop.Med. Int. Health, 1: 139146 (1996).

Oberlander, L. and Elverdan, B.: Malaria in the Unites Republic of Tanzania: Cultural considerations and health seeking behavior. Bull. WHO, 78: 13521357(2000).

Ongore, D., Kumani, F., Knight, R. and Munawa, A.: A study of KAP of a rural community on malaria mosquitoes. East African Med. Journal, 66: 79-90 (1989)

Press, I.: Problems in the definition and classification of medical systems. Soc. Sci. Med., 14b(3): 45 (1980)

Raikes, A.: Women's health in East Africa. Soc. Sci. Med., 28: 447-459 (1989).

Ramakrishna, J., Brieger, W.R. and Adeniyi, J.D.: Treatment of malaria and febrile convulsions: an educational diagnosis of Yoruba beliefs. International Ouarterly of Community Health Education. 9: 305-319 (1988-89).

Ruebush, T.K., Kern, M.K., Compbell, C.C. and Oloo, A.J.: Self-treatment of malaria in a rural area of Western Kenya . Bull. World Health Organ., 73(2): 229-236 (1995)

Salako, L.A.: Severe and complicated malaria in Africa. Malaria Infect. D is. Afr., 1: 22 (1994).

Salako, L.A, Brieger, W.R., Afolabi ,B.M., Umeh, R.E., Agomo, P.U., Asa, S., Adeneye, A.K., Nwankwo, B.O. and Akinlade, C.O.: Treatment of childhood fevers and other illnesses in three rural Nigerian Communities. J. Trop. Pediatr., 47(4): 230-238 (2001).

Snow, R.W.,Peshu, N., forster, D., Mwenesi, H. and Marsh, K.: The role of shops in the treatment and prevention of childhood malaria on the coast of Kenya. Trans. Roy. Soc. Trop. Med. Hyg., 86: 237239 (1992).

Spencer, H.C., Kaseje, D.C., Collins, W.E., Shehata, M.G., Turner, A., Stanfill, P.S., Huong, A.Y., Roberts, J.M., Villinski, M. and Koech, D.K.: Community based malaria control in Saradid Kenya: description of the programme and impact on parasite rates and antimalarial antibodies Ann. Trop. Med. Parasitol., 81(Suppl 1): 13-23 (1987).

Tanner, M. and Vlassoff, C.: Treatment-seeking behaviour for malaria: a typology based on endemicity and gender. Soc. Sci. Med., 46(4-5): 523-532 (1998).

Winch, P.J., Makemba, A. M., Kamazima, S.R, Lurie, M., Lwihula, G.K., Premji, Z., Minjas, J.N. and Shiff, C. J.: Local terminology for febrile illnesses in Bagamoyo district, Tanzania and its impact on the design of a community based malaria control programme. Soc. Sci. Med., 42: 1057-1067 (1996).

Winch, P.J., Wagman, J.A., Khatib, R.A., Lynch, M.C. and Massi, M.: Identification and characterization of traditional healers specialized in the treatment of severe malaria in Kongwa Distruct, Tanzania. Trop. Med. Int. Health, 79(11): 1014-1023(.2001).

World Health Organization. World Health Report 2002: Reducing Risks, Promoting Healthy Life. WHO, Geneva (2002). 
World Health Organization. Country Strategies and Resources Requirements (2003\}. From <http: I/mosquito. who.int/docs/strategy/nigeria.htm.> (retrieved August 2004).
Yenenah, H., Gyorkos, T.W., Joseph, L., Pickering, J. and Tedla, S.: Antimalarial drug utilization by women in Ethiopia: A knowledge-attitude-practice study. Bull. WHO, 71(6): 763-772 ( 1993). 